\title{
Cotidiano
}

\section{DO FILME “OBSESSÃO” À ANÁLISE COTIDIANA}

\author{
Graziela Oliveira Miolo Cezne (1) \\ Camilla Baldicera Biazus (2)
}

\begin{abstract}
Resumo
Não pode-se negar a proximidade entre o cinema e os fatos da vida real. Quando relacionamos o cinema e a psicanálise, observa-se que estes campos ocupam-se das mais variadas e desconhecidas emoções humanas, ao mesmo tempo que contribuem para a (re)construção de novas subjetividades. Diante disto, propõe-se aqui a análise do filme Obsessão que relata a história de uma mulher que deseja tornar-se mãe a qualquer custo e que tendo o seu filho, estabelece com esse uma relação simbiótica. Tenta, até o último momento, proibi-lo de ter contato com outras pessoas, inclusive com seu pai. Através desta análise objetiva-se refletir, baseando-se na teoria psicanalítica, sobre o desejo materno e consequentemente sobre as funções materna e paterna na contemporaneidade.
\end{abstract}

Palavras-chave: Filme Obsessão, maternidade, paternidade, psicanálise

\section{Introdução}

A arte cinematográfica, ou a mais conhecida sétima arte, vem ao longo do tempo ilustrando recortes da vida cotidiana, como: relacionamentos familiares, relacionamentos amorosos, conflitos adolescentes, entre outros. Muitas vezes esses recortes baseiam-se em fatos reais, outras vezes, embora ficção, os fatos transpostos na tela do cinema demonstram tanta realidade que parece inevitável identificar com casos reais da vida humana. A explicação para tal aproximação abriga-se no centro dessas duas experiências, afinal, tanto na vida cotidiana, quanto no cinema, o ser humano é que torna-se construtor e idealizador.

No cinema, o autor de um filme (um artista), bem como a direção e atores, trabalham a partir de suas vivências, de suas subjetividades. E o homem em seu cotidiano constitui sua 
subjetividade através de suas vivências, e vice-versa. É nesse ínterim que o encontro entre a psicanálise e o cinema acontece com total propriedade, uma vez que ambos tem sua atuação perpassando pelas construções subjetivas da humanidade.

Frente a isso, pretende-se trabalhar na perspectiva de análise do filme "Obsessão", contemplando também questões referentes à parentalidade cotidiana, revelando um determinado "enfraquecimento" da função paterna na contemporaneidade. Assim, objetiva-se construir um alicerce teórico a fim de compreender o sujeito da contemporaneidade, e com isso sua subjetividade, e seus processos de subjetivação.

\section{“Obsessão": A maternidade de uma perspectiva tóxica}

O filme em questão, fugindo de uma possível visão caricata, retrata a busca doentia de uma mulher, Emily, para tornar-se mãe, executando com isso um modo de funcionamento psicótico, e estabelecendo com o filho um relacionamento da mesma ordem. Emily, é uma personagem bem sucedida financeiramente graças a herança deixada pelos pais e que tem como principal objetivo de vida ser mãe.

Nesse desejo de ter este outrem em sua vida, estabelece relacionamentos sexuais com vários homens, variando porte e características físicas, nível intelectual, desejando e acreditando que cada um desses sujeitos pudesse contribuir com o que tivessem de melhor para aquela criança. Emily chega ao ponto de dizer que ela não tem mais interesse em homens, e sim em um filho, tornando possível inferir que a criança passa a ocupar um lugar de objeto no seu desejo.

Frente a essas considerações é possível fazer referência à Freud (1914) quando conceitua o Complexo de Castração, compreendido aqui como um processo de afastamento materno, onde a filha introduz o pai na vida sexual. Relacionando este conceito à análise do filme em questão é possível inferir que o autor sinaliza é a busca objetiva da mulher pelo pênis do qual acredita ter sido privada. Já que a menina não consegue ter o pai, pelo impedimento da mãe (estruturação do Complexo de Édipo), ela recorre então a outros meios de obtenção desse pênis.

O desejo que leva a menina a voltar-se para seu pai é, sem dúvida, originalmente o desejo de possuir o pênis que a mãe lhe recusou e que agora espera obter de seu pai. No entanto, a situação feminina só se estabelece se o desejo do pênis for substituído pelo desejo de um 
bebê, isto é, se um bebê assume o lugar do pênis, consoante a uma primitiva equivalência simbólica (FREUD, 1932, p. 158).

Ainda nesta perspectiva, o filme continua mostrando que após esta busca, quase que maníaca, esta mulher descobre que seu desejo não se realizou, e que não está grávida. Tal fato ocorre, no momento em que sente ter ficado menstruada. Neste instante, entra em total devaneio, culminando com um comportamento quase que inerte. Emily, se apresenta como se estivesse vazia, e após um tempo, conhece Paul, um homem, pelo qual implicitamente parece sentir algum tipo de desejo (quiçá o de filho?), mas não apenas de posse (uso e desuso). Este homem ao que tudo indica também demonstra por ela tal afeto e mantém relações sexuais, desaparecendo logo após.

Desta relação com Paul resulta a gravidez de Emily, que dará luz a um menino que levará o nome de seu pai - Paul - mesmo não mantendo nenhum tipo de contato com este (escolha simbólica da nomeação do pênis-seu pênis-objeto?). Neste ponto faz-se importante elencar as considerações feitar por Aulagnier (1990), quando menciona que antes mesmo do sujeito nascer existe um investimento (uma inscrição?),conceituada como a representação fantasmática, constituindo aquilo que ela chama de eu antecipado, permitindo a esse sujeito o acesso a linguagem fundamental (aquela que organiza a família e os afetos), estando interposta pelo desejo do pai, também como organizador e estruturador do desejo do filho.

Aulagnier (1990) chama a atenção para o lugar do desejo materno e paterno de ter filho, ou de ter uma criança. Ou seja, é fundamental o sujeito poder ter conhecimento de sua história de origem, alicerçada pela sexualidade do casal parental, porque esta é a causa do desejo de um pai por uma mãe, e vice versa. Portanto, para a autora, o desejo tem duas metas: desejo de desejo e desejo de não desejo. O primeiro seria o que diz respeito ao desejo de um filho (pulsão de vida), alguém que tenha desejo, inclusive de ter filho. O segundo diz respeito ao desejo de maternidade (pulsão de morte), alguém que reconstrua uma repetição, um objeto, parte de si.

Portanto, nesse entendimento psicanalítico de Aulagnier, torna-se relevante mencionar que a vida de Paul, ao lado da mãe, torna-se "a própria mãe". Isto ocorre porque o menino é cerceado pela mãe de todo e qualquer contato com o mundo: não é permitido que tenha amiguinhos, não é permitido que vá à escola, não é permitido que sequer tenha um animal de estimação (sua mãe mata o passarinho pelo qual a criança se apega), porque não é permitida a entrada de nenhum terceiro nesta relação. 
Como forma de reafirmar a execução de um relacionamento simbiótico com o filho, Emily faz questão de se mudar para cidades pequenas, onde o modo de vida de Paul ficará mais facilmente sob seu controle. Nestas pequenas cidades, quando havia a tentativa de algum terceiro aproximar-se, era sempre visto como uma ameaça quase que mortal ao seu relacionamento com o filho. Isto fica claro na situação em que uma vizinha pega Paul, ainda bebê, no colo, e este se aninha no seu seio, enquanto a mãe está distraída. Quando esta vê a cena do seu nenê sendo amamentado por um terceiro ela entra em desespero, desencadeando quase um quadro de surto. Fato esse que se encaixa perfeitamente ao que foi mencionado anteriormente sobre o desejo de pênis, referenciado pela obra freudiana e o desejo de maternidade, referenciado pela obra de Aulagnier.

No entanto, a produção cinematográfica revela que apesar de todas estas tentativas de corte da conexão de Paul com a realidade externa, faz com que ao passar dos anos, o próprio menino exija que sua vida seja como a dos demais meninos da sua cidade que ele observa pela vizinhança. Neste momento começam a surgir os conflitos na relação entre mãe e filho, uma vez que ele próprio acaba exigindo seu ingresso no colégio. No entanto mesmo conseguindo ir ao colégio, Paul é boicotado quase diariamente por sua mãe que vai ao colégio e o tira da sala de aula mais cedo, com a desculpa de levá-lo ao médico. Tal investida tem sucesso até o dia em que Paul dá-se por conta das mentiras da mãe, e percebe que ela não tem poder de ler seus pensamentos. Ou seja, é através da fantasia, que Paul consegue estabelecer uma conexão mais sadia com a realidade.

Nesta direção, faz-se pertinente retomar o entendimento psicanalítico Aulagnier (1990), que destaca como sendo condição vital para o funcionamento do eu, o direito e a possibilidade de criar pensamentos, ou simplesmente de pensar, exigindo com isso o direito de escolher os pensamentos que comunica e aqueles que guardam segredo. Nesta perspectiva, acredita-se que Paul fez de seu segredo de pensar, a construção de suas fantasias, pois conforme discorre Aulagnier (1990, p. 263):

A possibilidade do segredo faz parte das condições que permitirão ao sujeito, num segundo tempo, atribuir o estatuto de fantasia a algumas de suas construções ideacionais que por isso são diferenciadas do conjunto de seus pensamentos: a finalidade e o prazer que ele espera disso serão do mesmo modo diferenciados, o pensamento que age e o pensamento que encontra em si mesmo sua própria razão de ser poderão estar separados. 
Analisando o filme, reconhece-se neste momento da identificação da separação do pensamento e daquilo que virá a ser sua fantasia, uma construção sadia de Paul (seu momento de libertação ou talvez, de conexão com a neurose). Reafirma-se tal fato ainda através dos entendimentos de Aulagnier (1990), quando menciona que a neurose permite ao sujeito preservar seu direito de manter pensamentos secretos, assumindo isto de forma natural. Enquanto que na psicose não se reconhece o estatuto de separar aquilo que é uma fantasia daquilo que não o é. Esse reconhecimento do Eu que Paul parece desenhar através da capacidade de pensar (fantasiar), ou do direito ao segredo, transparece como aquilo que não foi permitido, ou investido na vivência de Emily.

O fato é que o filme desenrola-se demonstrando as situações de um relacionamento tóxico de Emily com Paul, no qual a mãe busca desesperadamente cercear o filho do contato com o mundo externo. Entretanto, o filme acrescenta à essa história, as vivências desta mãe enquanto filha. Assim, são feitos recortes da vivência da família nuclear desta mãe que tem no relacionamento dos pais um alicerce, talvez, para constituição desta personalidade doentia. Vê-se tal fato, pois os pais desta mãe mantêm uma relação bastante infantilizada onde ambos bastavam-se e a filha era vista como algo "à parte", da relação dos dois. Este relacionamento chega ao ponto do casal cometer suicídio em conjunto, deixando apenas uma carta para filha. De forma "nebulosa" acredita-se que o resgate da história familiar de Emily teve como intuito demonstrar a falta de investimento dessa em sua mãe, a tal ponto que não fosse possível estruturar e reconhecer o desejo de desejo, anteriormente disposto sob a obra de Aulagnier.

Conectando estas questões abordadas no filme com a realidade, pretende-se novamente transpor aquilo que Freud (1914), discorre sobre o complexo de castração: aquilo que emana da questão da mulher ambicionar ter um filho do seu pai (obtendo assim o pênis), mas se impedida (proibição do incesto), e ao atingir sua feminilidade, buscar então um parceiro que lhe proporcione esse filho (ser social). Nesta direção, pode-se então elencar questões referentes à fertilização artificial ou reprodução assistida, contemplando a perspectiva de Jerusalinsky (1999), quando fala da educação na atualidade, referindo o fato do saber do pai deslocar-se para a ciência, sendo que essa toma o objeto como fonte de saber concretizando o real e destituindo o simbólico.

Seguindo a linearidade do pensamento do autor anteriormente referido é possível inferir que a procura de um parceiro não perpassa mais o desejo por um homem, mas sim por um saber, o que acaba dando origem a um casal parental constituído pela mãe de um lado e pela ciência de outro. Esta constatação vem ao encontro do filme aqui analisado, quando 
mostra que Emily em seus relacionamentos amorosos não tem mais um interesse por homens, mas sim por um filho.

$\mathrm{Na}$ vivência postulada pelo filme, e no que se pretende neste ensaio, refere-se que o estabelecimento de uma relação a tal ponto doentia seria exercido por esta destituição do simbólico referido ao pai, ocasionando o investimento do não desejo também no que concerne a direção do desejo do pai (sexualidade do casal parental $\rightarrow$ reconhecimento de sua origem). Esta parece ser a proposta de análise do filme, chamar a atenção para a arte do investir, a possibilidade de desejar, e dar um entendimento àquilo que é investido, e também para o que é feito a partir disto.

Faz-se referência a esta questão, porque assim como o destino dos avós de Paul, foi o suicídio, até certo ponto, este parece ser também o destino de Paul. Trancafiados na garagem a mãe liga o carro, desconecta o cano de descarga e espera que a morte chegue. Neste momento a morte parece ser o único terceiro capaz de entrar na relação dos dois, porque talvez nesta "invasão" permaneçam juntos (ou a mesma pessoa) pela eternidade.

No entanto este momento parece ser o ponto culminante de libertação, que Paul está ensaiando desde o início do filme: é através da fantasia que esta mãe tenta aprisionar Paul na relação, e dentro do carro, numa viagem que os levará a morte. Pois é através da fantasia que Paul, pelo menos momentaneamente, liberta-se, e retorna a vida (ou renasce), porque a mãe morre, e ele consegue escapar de dentro do carro. A morte desfaz aquele ponto de união insana e permite que Paul trilhe seu próprio caminho, mas talvez ainda com a mãe, não na presença física, mas na herança de toda sua identificação com ela.

Nesta perspectiva é possível retomar as disposições de Aulagnier (1979) quando discorre a respeito do que denomina como identificação com aquilo que é investido sob o eu. Assim, a imagem de si projetada no futuro, deve proporcionar esperança de se tornar imagem identificatória, valorizada pelo sujeito e pelo meio, ou por um subgrupo privilegiado pelo sujeito.

\section{Ficção X Realidade}

Neste ínterim, deixa-se de lado a idéia cinematográfica e submete-se à análise cotidiana, da realidade em si. Wagner (2005) destaca que a família atual apresenta um novo perfil, caracterizado por importantes fenômenos e movimentos sociais, como: a entrada das 
mulheres no mercado de trabalho e sua maior participação no sistema financeiro familiar. Esse modelo contrapõe-se à estrutura familiar tradicional, que tinha o pai como o único provedor. E a mãe como a única responsável pelas tarefas domésticas e cuidado dos filhos. Em sua pesquisa a autora percebeu que atualmente está ocorrendo uma transição de papéis, e o casal está assumindo a divisão de tarefas, na qual pais e mães compartilham aspectos referentes às tarefas educativas e organização do dia-a-dia da família. Este modelo atual de família substitui, segundo Gomes e Resende (2004), o modelo hierárquico, sem deixar lugar para o autoritarismo do antigo pai, provedor do lar e ditador dos princípios éticos, e da mulher submissa, mantenedora e provedora dos cuidados domésticos e dos filhos, com dedicação exclusiva à isso. Nesta nova estrutura o homem vê-se surpreendido com o constante questionamento de sua autoridade rompendo com a hierarquia doméstica onde ele encontravase no topo.

Entretanto, esta mudança de contexto não retirou o pai de seu silêncio, ele ainda se encontra, em muitas famílias, excluído do relacionamento afetivo familiar. No filme vimos que a mãe de Paul opta por não revelar ao filho quem é o seu pai, nem mesmo em pensamento, não delegando a ele nem o papel de progenitor. Paradoxalmente a isto, reflete-se sobre o cotidiano, cada vez mais freqüente, de pais que lutam por novos horizontes que não apenas o de progenitor, já que perderam em parte seu papel de provedores financeiros do lar. Diante desta realidade, percebe-se que esses homens estão dispostos a redefinir seu papel, a restabelecer seu lugar e a repensar modelos que lhe permitam viver a paternidade, senti-la e exteriorizá-la bem como a construir sua subjetividade de pai, enfrentando as demandas que este novo papel traz (GOMES e RESENDE, 2004).

Esta redefinição de papéis na contemporaneidade é um elemento imprescindível para a construção subjetiva dos filhos, pois, retomando o pensamento de Augnalier (1979), o papel do pai é indispensável para a construção do eu do infante. Como já mencionou-se anteriormente na análise do filme, Paul na sua história de vida caminhou rumo a psicotização, sem ter a presença do pai ao seu lado e submerso em uma relação simbiótica com sua mãe. Muitas configurações familiares têm se formado atualmente como as tecnologias médicas, ou ainda a chamada produção independente, que desvalorizam a função subjetiva do pai, tirando seu papel, sua liberdade de desejar um filho.

Frente a este enfraquecimento cada vez maior da função paterna na contemporaneidade, faz-se referência aqui às considerações de Aulagnier (1979) uma vez que enfatizam a delimitação de um espaço de constituição do eu que inclui o pai, bem como o seu desejo de ter um filho e a importância do seu encontro com a criança. A oportunidade de 
estabelecer um relacionamento com o pai ou de ter a referência de uma figura paterna foi negado à Paul, no filme, e reflete também a realidade de muitas famílias contemporâneas que se encontram marcadas por crises de diversas ordens nos seus vínculos afetivos.

No filme, Emily, desejava o filho só para ela, não queria de forma alguma a intervenção de terceiros, quem dirá a do pai, visto como um elemento altamente ameaçador para o relacionamento mãe-filho. Esse sentimento de posse pela criança, que passa a ser tomada como um objeto, provoca indagações a respeito daquelas mães que recorrem à produções independentes. De que ordem é este desejo pela maternidade? Que significado essa criança tão almejada inscreve na estrutura psíquica dessa mãe? Sabe-se, de acordo com o que vem sendo exposto, que a mãe deve além de desejar ter um filho, desejar dar um filho ao homem ao qual ela escolheu, e a criança recebe da mãe esse desejo, podendo assim também reconhecer esse pai como fonte de afeto. Assim, de acordo com Aulagnier (1979,p.138): “O desejo materno do qual a criança é herdeira, condensa duas relações libidinais: a que a mãe tinha estabelecido com a imagem paterna e a que ela vive com aquele a quem ela, efetivamente, deu um filho".

O encontro da criança com o pai, a referência à figura paterna é propiciada pela mãe, no seu discurso ao bebê. É a mãe que permite a entrada positiva do pai para o filho, já que é ela a primeiro representante do Outro (expressão lacaniana) para a criança. E o pai, nesta dinâmica, torna-se o primeiro representante dos Outros, ou seja, o pai apresenta a criança ao meio, quebrando com o relacionamento exclusivo mãe/bebê. Esse encontro proporciona à criança o mundo. O infans percebe que o "outro sem-seio" (expressão de Piera Aulagnier para se referir ao pai) é fonte de afeto e não proporciona as necessidades básicas do corpo, como a mãe o faz. É neste momento que a criança dá-se conta de suas necessidades libidinais.

Nesta descoberta o pai torna-se objeto a seduzir como objeto de ódio, pois o pai que o acalenta é o mesmo que a mãe deseja, ou seja, a criança dá-se conta que não é o único objeto de amor e que por isso não concede a ela o prazer pleno a mãe. Sendo assim, a criança perce que deve então também submeter-se à lei do pai, fazendo-a, em seu ódio, desejar a morte deste rival que ocupou seu lugar. Ódio também sentido por seu pai na tenra idade, mas que agora tem-se livre pois transmitiu ao seu filho. Nesta configuração o pai é quem reprime este desejo, dando ao filho, através de seu nome, de sua lei, o direito de herdar seus dons, e futuramente também tornar-se pai. Direito esse passado de pai para pai.

Nesta direção Aulagnier (1979, p. 138) discorre que: 
$\mathrm{Na}$ estrutura familiar da nossa cultura, o pai representa aquele que permite à mãe designar para a criança, na cena do real, um referente garantindo que seu discurso, suas exigências e suas interdições escapam ao arbitrário e se justificam por sua conformidade a um discurso cultural, o qual lhe delega o direito e o dever de transmiti-los.

Sendo assim a mulher com toda sua importância na criação dos filhos, não pode dar isso ao seu bebê. E se não permite a entrada deste homem desejante na vida de seu filho, está fazendo o mesmo movimento realizado pela mãe de Paul na ficção, voltando seu filho para o mundo da fantasia, afastando-o do real, da sociedade, da vida.

\section{Considerações Finais}

Frente às reflexões e considerações construídas aqui, finaliza-se este estudo, apenas como forma de estruturação textual, mas longe de pretender dar um ponto final em discussões acerca desta questão. Enfatiza-se a necessidade de ampliar as discussões e reflexões acerca das mudanças ocorridas na sociedade hoje, o surgimento de novos papéis e principalmente a importância do casal parental na criação dos filhos.

A figura masculina historicamente sempre foi deixada de lado no que diz respeito a transmissão da afetividade. Entretanto observa-se na atualidade que os homens buscam desmistificar sua posição de "sexo forte" em relação as mulheres, frequentemente designadas pelo senso comum como o "sexo frágil".

Diante disto deixa-se então a seguinte reflexão: hoje cada vez mais o ser humano preserva sua individualidade, busca estruturar-se financeiramente, "corre" atrás de seus ideais, muitas vezes sacrificando, seus relacionamentos afetivos, bem como a formação de laços fortes com os filhos e seu par. Deixam a criação dos filhos na responsabilidade de terceiros, e sua vida afetiva de lado. Faz-se necessário que o ser humano revise seus valores, elabore suas dificuldades psíquicas, busque melhorar. As crianças merecem um ambiente mais saudável para que possam construir sua subjetividade, e para isso a família tem que ser a base para um futuro seguro e sem sofrimentos desnecessários. Uma base que transmita afeto, amor, ética e princípios. Vê-se cada vez mais na prática clínica, crianças com patologias como: anorexia e bulimia, obesidade infantil, depressões, futuras toxicomanias, síndrome do pânico, as alienações, futuros viciados em jogos, enfim, as crianças já mostram seu sofrimento, seu abandono desde muito cedo. Que espécie de adultos a sociedade quer e espera ter? 


\section{Referências}

ASSOCIAÇÃO PSICANALÍTICA DE PORTO ALEGRE. Educa-se uma criança?. $2^{\mathrm{a}}$ ed. Porto Alegre: Artes Ofícios, 1999

AULAGNIER, Piera A Violência da Interpretação - Do Pictograma ao enunciado- Rio de Janeiro: Imago, 1979

AULAGNIER, Piera. Um intérprete em busca de um sentido I,São Paulo:Escuta,1990.

FREUD, Sigmund. Obras Completas de Sigmund Freud. Ed. Standard Rio de Janeiro: Imago, 1996, v. XXII

Sigmund. Obras Completas de Sigmund Freud. Ed. Standard Rio de Janeiro: Imago, 1996, v. XXI

GOMES, Aguinaldo; RESENDE, Vera. Psic.: Teor. e Pesq. v.20 n.2 O pai presente: o desvelar da paternidade em uma família contemporânea. Brasília. 2004

WAGNER, Adriana. Psicologia Teoria e Pesquisa. vol.21 no.2. O pai presente: o desvelar da paternidade em uma família contemporânea. Brasília. 2005

\section{Sobre as Autoras:}

(1) Graziela Oliveira Miolo Cezne é Psicóloga pelo Centro Universitário Franciscano (UNIFRA). Mestre em Psicologia Clínica pela Universidade do Vale do Rio dos Sinos (UNISINOS). Especialista em Clínica Psicanalítica pela Universidade de Santa Cruz do Sul (UNISC).

Email: grazielamiolo@hotmail.com

(2) Camilla Baldicera Biazus é Psicóloga pelo Centro Universitário Franciscano (UNIFRA). Mestranda em Psicologia Clínica pela Universidade do Vale do Rio dos Sinos (UNISINOS).

Email: camillabiazus@yahoo.com.br

\section{Como citar este artigo (Formato ISO):}

CEZNE, Graziela O.M. e BIAZUS, Camilla B. Do filme "Obsessão" à análise cotidiana. Id on Line Revista de Psicologia, Novembro de 2010, vol.1, no.12, p.06-15. ISSN 1981-1189. 